\title{
Media Reports of Unintentional Opioid Exposure of Public Safety First Responders in North America
}

\author{
Paul Alexander Herman ${ }^{1} \cdot$ Daniel Saul Brenner $^{1} \cdot$ Stewart Dandorf $^{1} \cdot$ Stephanie Kemp $^{1} \cdot$ Breann Kroll $^{1}$. \\ Joshua Trebach ${ }^{1} \cdot$ Yu-Hsiang Hsieh ${ }^{1}$. Andrew lan Stolbach ${ }^{1}$
}

Received: 24 January 2020 / Revised: 29 January 2020 / Accepted: 2 February 2020 / Published online: 24 February 2020

(C) American College of Medical Toxicology 2020

In 2018, more than 48,000 Americans died from opioid overdose, with synthetic opioids such as fentanyl contributing to more than half $[1,2]$. Public safety first responders, including law enforcement officers and emergency medical service (EMS) providers, encounter opioids in the field during law enforcement operation responses to opioid overdoses [3]. Because opioids kill by suppression of breathing, timely first responder response may be the difference between life and death.

In 2016, commenters on an online medical toxicologist discussion forum made us aware of unverified reports that first responders themselves may be at risk from unintentional opioid exposure from small amounts of drug on patient clothing or in the air. These reports were attributed to lay media or discussions with EMS personnel. In response to similar reports, federal agencies issued guidance on addressing these potential exposures as early as 2016 [4, 5]. In September of that year, the United States Drug Enforcement Agency (DEA) warned "fentanyl can be absorbed through the skin or through accidental inhalation of airborne powder" [6]. In a June 2017 DEA video, the Acting Administrator advised not to touch fentanyl "without the proper personal protective equipment" [7]. This statement was accompanied by an image of level A personal protective equipment (PPE), consisting of a positive pressure suit with self-contained breathing apparatus.

The consensus of the scientific community remains that illness from unintentional exposures is extremely unlikely, because opioids are not efficiently absorbed through the skin and are unlikely to be carried in the air [8]. In a rare case report

Supervising Editor: Mark B. Mycyk, MD

Andrew Ian Stolbach

astolba2@jhmi.edu

1 Department of Emergency Medicine, Johns Hopkins University, Baltimore, MD, USA of law enforcement officer opioid exposure in a peer-reviewed literature, clinical manifestations were not consistent with opioids, and none of the law enforcement officers tested was positive for opioid metabolites [9]. In other words, the phenomenon of first responder opioid exposure that seemed to be frequently reported in news media has not been confirmed scientifically. Nevertheless, these media reports led to recommendations for higher level PPE for emergency responders.

On the surface, it may seem like a reasonable, conservative recommendation to encourage emergency responders to wear maximum protective equipment if there is any small chance of unintentional opioid exposure. However, unnecessary PPE may delay emergency care to opioid-poisoned patients [4]. A short delay in response can be lethal for a patient who is not breathing.

We wanted to investigate the initial lay media reports to understand where they came from and what they reported. We were curious to see how these media reports concluded first responder exposure when we could not find any confirmation in the scientific literature. Using a team of five reviewers, we searched LexisNexis for English-language print and online lay publications on first responder opioid exposure published in North America between January 2012 and March 2018. We randomly assigned articles to one of the five reviewers who used a standardized data collection form. We set aside articles that did not mention a specific case of first responder exposure. (Many articles discussed the issue without reporting a specific case.) If the article reported an exposure to a first responder, the reviewers recorded the route of exposure, the documented clinical manifestations, and whether any confirmatory drug testing was described.

Our initial search yielded 1408 articles, but after review, only 1016 were relevant to the topic of first responder opioid exposure. Of the relevant articles, 214 actually described first responder opioid exposure. To confirm an exposure, we looked for articles that described a plausible exposure pathway accompanied by convincing symptoms and confirmatory 
laboratory testing. Of the 214 articles that reported exposure during this period, our reviewers did not find a single one that reported a plausible route of exposure, clinical manifestations consistent with exposure, and laboratory testing that confirmed exposure.

The very first article describing a first responder exposure was published in the Gazette (Montreal) on May 14, 2013 [10]. In the story, officers entered an illicit Canadian facility that manufactured drugs, including desmethylfentanyl. One officer was taken to a hospital with "heart problems," while three others, who handled drugs wearing masks and gloves, developed rashes on their arms. The reporting in this article demonstrated many of the issues seen in subsequent articles. The symptoms were not consistent with opioid poisoning (neither heart racing nor rashes are symptoms of opioid toxicity), and no confirmatory testing was described. Seemingly, the only "proof" of exposure was that the victims thought they were exposed.

After this first report, there were few articles describing exposures until 2016, when reports resumed. There was a spike of lay media reports of first responder opioid exposure in Q2 and Q3 of 2017 (see Fig. 1).

Subsequent articles showed similar shortcomings. In fact, we only found one incident, described on September 14, 2016, in two British Columbia newspapers, with any mention of laboratory testing of an exposed individual. In this case, an officer responded to assist a young man found unconscious in a car, smelled a "chemical odor," and became nauseated and dizzy $[11,12]$. "Tests at a hospital later showed his heart rate and blood pressure were elevated. Traces of opiates were found in his urine."

This description of opiate testing deserves further examination. The reported finding of "traces of opiates" probably does not point to the opioid fentanyl or its analogs, because these substances are not detected by opiate screens. We considered that a reporter not familiar with opioid terminology may erroneously substitute the word "opiate" for "opioid," but fentanyl immunoassays were not commercially available for clinical use in 2016, so it is unlikely that a test was used that could have found fentanyl [13]. "Traces of opiates" probably refers to a standard opiate immunoassay, which would identify codeine, morphine, and heroin, but not fentanyl or its analogs. Moreover, for all common urine drug testing, a positive test does not confirm acute exposure; the broad detection intervals for these assays mean that positive tests indicate exposure within the last several days. In the above case, the reported exposure does not contain a plausible route of exposure, symptoms consistent with exposure, or well-described laboratory confirmation of exposure.

Because the scientific literature does not contain confirmed first responder exposures, lay media reports remain the only "evidence" of the phenomenon. As a result of these articles and other media reports, despite recommendations from experts that standard gloves are sufficient in most cases, regulatory agencies have recommended unnecessary PPE, and manufacturers have advertised products to EMS to protect against skin absorption of fentanyl $[6,14]$.

Scientific publication is a deliberate, peer-reviewed process that primarily reaches scholars, while the lay media can quickly and widely disseminate information.

A joint ACMT-AACT position statement - the first scientific guidance to clarify the low likelihood of exposure-was not published until December 2017 [8]. There was a sixmonth period of time where unvalidated first responder exposures were not challenged in scientific journals. As scientists, we must reach out to local media to offer information to clarify misleading narratives.

Why has there been such a discrepancy between media reports and scientific consensus? In most cases, the emergency responders in these reports were experiencing real symptoms that they attributed to an opioid exposure, and the writer reported that conclusion as a fact. In reality, individuals might not know why they felt ill or what caused their symptoms.
Fig. 1 Spike of lay media reports of first responder opioid exposure in Q2 and Q3 of 2017.
MEDIA-REPORTED FIRST RESPONDER OPIOID EXPOSURES BY QUARTER

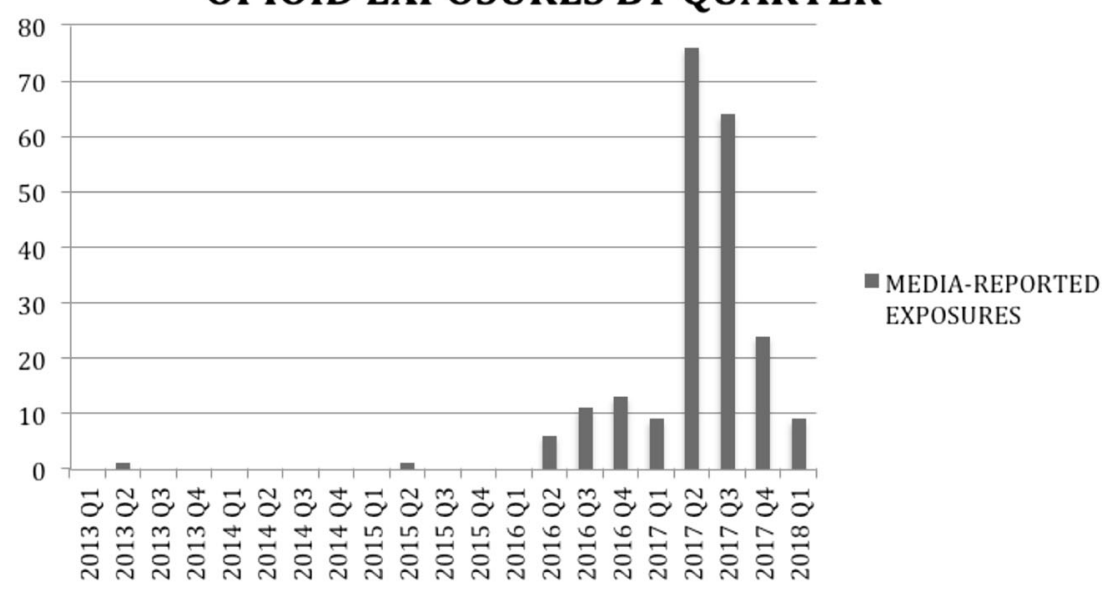


Symptoms such as rapid heart rate or rash are not consistent with opioid toxicity. These symptoms may have other causes, including psychological stress or skin irritation from PPE. Many of these first responders were administered naloxone or transported to a hospital as a precautionary measure. When a news story reports that a patient was given naloxone and treated for opioid exposure, the story should clarify that receiving treatment and observation is not the same as requiring treatment and observation. Because of patient privacy concerns, stories report that a first responder was "treated" for opioid exposure without input from the treating physician to clarify that such treatment was precautionary and did not confirm the exposure $[5,15,16]$.

In fact, media reports about adverse effects of other environmental stimuli may actually increase the likelihood of other emergency responders experiencing symptoms in the future. Study subjects exposed to news stories about health effects of Wi-Fi exposure experienced tactile symptoms even when exposed to sham Wi-Fi signals $[17,18]$. The authors hypothesized that sensationalized reports sensitized people to develop a nocebo effect-symptoms of illness caused by negative expectations following an exposure. According to this hypothesis, it is plausible that unverified reports of opioid exposure actually contribute to causing illness among FRs.

Perhaps the greatest danger of first responder fear of exposure is delayed response to overdose victims. When treating opioid overdose, every second matters, and unnecessary delay of rescue breathing and naloxone administration may be costly. Recommendations for extra personal protective equipment result in first responder discomfort and delayed performance of critical tasks [4].

We should take all necessary precautions to ensure the safety of first responders. These men and women provide health care in the most challenging environments. As physicians and scientists who support these health professionals, we owe them accurate information. The conclusions reached by the two major clinical toxicology professional groups still hold [8]:

(1) Unintentional exposure is unlikely because opioids are not absorbed well through the skin and are unlikely to be present in the air;

(2) Standard nitrile gloves should be worn during patient contact;

(3) A mask is only needed in the unlikely circumstance drug is in the air;

(4) Any powder found on the skin should be decontaminated with soap and water; and

(5) Naloxone should be reserved for patients with symptoms of opioid poisoning, such as respiratory depression.

We call on better collaboration between scientists and reporters covering the opioid epidemic. News stories on suspected first responder exposures should attempt to determine if confirmatory testing was performed, include input from an expert who can state whether symptoms are consistent with opioid poisoning, and provide accurate information on physical properties of opioids that make unintentional illness extremely unlikely. Although first responders should continue to take reasonable precautions, analysis of lay media reports is consistent with the consensus of the medical community that unintentional first responder opioid poisoning from incidental contact is extremely unlikely.

Sources of Funding None

\section{Compliance with Ethical Standards}

Conflicts of Interest None

\section{References}

1. Ahmad FB, Rossen LM, Spencer MR, Warner M, Sutton P. Provisional drug overdose death counts. National Center for Health Statistics. 2018. https://www.cdc.gov/nchs/nvss/vsrr/drugoverdose-data.htm Accessed January 21, 2020.

2. United States Centers for Disease Control and Prevention. Opioid overdose. https://www.cdc.gov/drugoverdose/data/statedeaths.html Accessed January 21, 2020.

3. Davis CS, Ruiz S, Glynn P, Picariello G, Walley AY. Expanded access to naloxone among firefighters, police officers, and emergency medical technicians in Massachusetts. Am J Public Health. 2014 Aug;104(8):e7-9.

4. Lynch MJ, Suyama J, Guyette FX. Scene safety and force protection in the era of ultra-potent opioids. Prehosp Emerg Care. 2018 Mar-Apr;22(2):157-62.

5. Pinckard C. Ohio police officer accidentally contacts fentanyl, overdoses. Cleveland.com. May 16, 2017. https://www.cleveland.com/ metro/2017/05/ohio_police_officer_accidental.html Accessed January 21, 2020.

6. Kulbarsh P. DEA warning to law enforcement: fentanyl and carfentanil exposure kills. Officer.com. Sept 30, 2016. https:// www.officer.com/investigations/article/12263320/dea-warning-tolaw-enforcement-fentanyl-and-carfentanil-exposure-kills Accessed January 21, 2020.

7. Roll call video warns about dangers of fentanyl exposure. United States Department of Justice. June 6, 2017. https://www.justice. gov/opa/video/roll-call-video-warns-about-dangers-fentanylexposure Accessed January 21, 2020.

8. Moss MJ, Warrick BJ, Nelson LS, McKay C, Dubé PA, Gosselin S, et al. ACMT and AACT position statement: preventing occupational fentanyl and fentanyl analog exposure to emergency responders. J Med Toxicol. 2017 Dec;13(4):347-51.

9. Chiu SK, Hornsby-Myers JL, de Perio MA, et al. Health effects from unintentional occupational exposure to opioids among law enforcement officers: two case investigations. Am J Ind Med. 2019 May;62(5):439-47.

10. Wilton K. Toxic drugs seized in police raids; emergency rooms notified of danger. Montreal Gazette. May 14, 2013:A4.

11. Bains, C. RCMP issuing drug overdose treatment. The Prince George Citizen. September 16, 2016:A4.

12. Bains, C. RCMP officers to get naloxone kits to deal with exposure to opioids. Times Colonist. September 14, 2016:A2. 
13. Grunbaum AM, Rainey PM. Laboratory principles. In: Nelson LS, Howland M, Lewin NA, Smith SW, Goldfrank LR, Hoffman RS, editors. Goldfrank's Toxicologic emergencies. 11th ed. New York: McGraw-Hill.

14. Halyard Health. Halyard health introduces fentantyl-resistant gloves to protect first responders. https://www.halyardhealth.com/ media/508936/BLACK-FIRE-fentanyl-claims-Media-Alert.pdf Accessed January 21, 2020.

15. McDaniels A, Butler E. Deputy, two EMS providers treated for overdose symptoms responding to call. May 23, 2017. https:// www.baltimoresun.com/health/bs-md-harford-opioid-exposure20170523-story.html Accessed January 21, 2020.

16. Queally J. LAPD officers hospitalized after exposure to fentanyl in North Hollywood. https://www.latimes.com/california/story/2019- 09-06/lapd-officers-hospitalized-after-exposure-to-fentanyl-innorth-hollywood Accessed January 21, 2020.

17. Bräscher AK, Raymaekers K, Van den Bergh O, Witthöft M. Are media reports able to cause somatic symptoms attributed to WiFi radiation? An experimental test of the negative expectation hypothesis. Environ Res. 2017;156:265-71.

18. Witthöft M, Rubin GJ. Are media warnings about the adverse health effects of modern life self-fulfilling? An experimental study on idiopathic environmental intolerance attributed to electromagnetic fields (IEI-EMF). J Psychosom Res. 2013;74:206-12.

Publisher's Note Springer Nature remains neutral with regard to jurisdictional claims in published maps and institutional affiliations. 